\title{
EFFECTIVENESS OF RECIPROCAL RULE IN TOURISM: EVIDENCE FROM A CITY TOURIST RESTAURANT
}

\author{
MICHAŁ ŻEMŁA, ${ }^{1}$ ANASTASIYA GLADKA ${ }^{2}$
}

\begin{tabular}{l|l} 
& $\begin{array}{l}\text { 'Pedagogical University in Cracow, POLAND } \\
\text { e-mail: michalzemla@gazeta.pl } \\
\text { 2Andrzej Frycz Modrzewsi University of Cracow, POLAND } \\
\text { e-mail: agladka3@gmail.com }\end{array}$ \\
$\begin{array}{l}\text { RECEIVED } \\
\text { ACCEPTED }\end{array}$ & $\begin{array}{l}10 \text { September } 2015 \\
10 \text { March } 2016\end{array}$ \\
JEL & $\begin{array}{l}\text { Z33, Z30, M12 } \\
\text { CLASSIFICATION }\end{array}$ \\
KEYWORDS & $\begin{array}{l}\text { reciprocity, restaurant, Cracow } \\
\text { The paper concerns the phenomena of reciprocal exchange which is know in social relations since ages and } \\
\text { also used in business relations. Reciprocity is also a popular tool in tourism business. Presented research were } \\
\text { conducted in a form of experiment in one of restaurants in Cracow city center. It was found that a small gift from } \\
\text { a waiter (a chewing gum) lead to an increase in tips. Surprised and feeling grateful customers decided to leave } \\
\text { a bigger tips than usually. }\end{array}$
\end{tabular}

\section{Introduction}

One of the strongest psychological tools, which is extremely popular in marketing circles, is reciprocity rule or the theory of reciprocal exchange, usage of which is showing very good response in many cases. The power of this rule is so universal, that applications of this rule could be met in all spheres of human life. This is one of a few 
examples, when the implication of one strategy allows receiving quite high level of positive response for minimum resources used.

Tourism is not an exception and the reciprocal rule is applicable also here on numerous of ways and fields. This is a quite common strategy used by different tourism companies, started with big international corporations, ending with small family run businesses in relations with their customers. However the strategy might be also applied in relations with suppliers or in relations between tourism employees and customers. The last case is the subject of presented research. The results presents how a waiter in a city restaurant may benefit thanks to a very simply use of reciprocal rule with minimum own effort and invest. The research were conducted in one of Cracow city-center restaurant being visited by numerous international visitors.

\section{The nature of reciprocal exchange in contemporary social relations}

In social psychology, the term „reciprocity” is usually associated with term "mutual exchange”. It is broadly used in common life and in last decades became popular in political circles. According to dictionary, reciprocity is seen as "a situation or relationship in which two people or groups agree to do something similar for each other" (http://www.merriam-webster.com/dictionary/reciprocity). Hence, the basic difference between reciprocity and mutual exchange is lying right in the basic process of two-way exchange: the word "mutual" refers to merely same actions from both sides; on the other hand, in the case of reciprocity actions of both actors may differ gradually in the scale of efforts, spending and actions taken (Gill, Postlethwaite, Seaford, 1998). Cialdini (2001, p. 75) defines reciprocity simply as, "People repay in kind." The effect has been found to be very robust. Reciprocity can either be paid back in kind (homomorphic) or with something of equal value (heteromorphic) (Diekmann, 2004). Not everyone reciprocates, and not everyone reciprocates equally (Clarkson, Frost, Sheffet, 2006, p. 54). The rule of reciprocal exchange can initiate an unequal exchange: small courtesy can generate a sense of gratitude, which forces to agree to provide a much more important and valuable response. This idea is perfectly used in the demo-versions of the products, free trials and etc. So, mutual exchange is seen as more mechanical and fare in comparison with reciprocity notion, where psychology plays a key role in shaping behavior.

As it was already mentioned, reciprocity is based under psychological techniques, which aimed to receive positive response after commitment of positive action, directed to concrete person. Nevertheless, the core idea of reciprocity is strongly linked to ethics that treat this term not only in respect to actions, but also in respect to the way of thinking. Famous "Golden Rule” or in other words "ethic of reciprocity” is known as: One should treat others as one would like others to treat oneself (Fehr, 2011). Consequently, the majority of examples of this reciprocal attitudes exchange mechanisms might be found in the closest environment and highlighted in routine communication with closest circle. This way of thinking usually refers to the roots from two sciences about human being: philosophy and sociology. Philosophically, it involves a person perceiving their neighbor as also an "I" or "self". Sociologically, this principle is applicable between individuals, between groups, and also between individuals and groups (For example, a person living by this rule treats all people with consideration, not just members of his or her in-group).

As a concept, the Golden Rule has a history that long predates the term "Golden Law", or "Rule of Reciprocity", as it was called from the 17th century in Central Europe. The feeling of gratitude was spread very widely, and, according to the sociologist $A$. Gouldner, it was the core trigger for the peace and development in all known societies. As a concept of "the ethic of reciprocity," as it is known nowadays, it has its roots in a wide range of world 
cultures, and scientists highlights that it was a standard way of resolving conflicts. The reciprocity was sparkling trust in people, which allowed them to equate it and unite with religion (Neusner, Chilton, 2008).

There are numerous examples of how reciprocity rule influence our social life. Those examples are also the subject of many scientific researches. Practitioners and researchers of social psychology, economics, and management have shown considerable interest in reciprocity for over two decades (Cialdini, 1993; Diekmann 2004; Clayson, Frost, Sheffet, 2006). For instance, Clayson (2004) discovered that reciprocity theory allowed explaining relations between the grades students had received and the grades that students had given to the lecturers. According to the results of their research students reward instructors who give them good grades and punish instructors who give them poor grades, irrespective of any instructor or preexisting student characteristic. Among the most popular ways of use of reciprocity in modern theory is using it as a tool of increasing sales and satisfaction of customers. Also there are numerous scientific researches showing how implementation of reciprocal rule may increase marketing effectiveness. According to Palmatier, Jarvis, Bechkoff and Kardes $(2009$, p. 1) reciprocity is, apart from trust and commitment, the cornerstone of successful relationship marketing. They discovered that relationship marketing investments generate short-term feelings of gratitude that drive long-lasting performance benefits based on gratitude-related reciprocal behaviors. Even though use of reciprocal rule is most common in achieving short-term goals, especially contemporary increase of sales.

\section{Chosen examples of application of recippocal rule to tourism}

Reciprocity in tourism is not a rare notion. Whole hospitality is based on this idea - if you create good atmosphere, show exceptionality and respect, not only it will be given back but also it will provoke additional sales of complementary products. If the tourist will be satisfied with perfect service in restaurant, he/she will leave bigger tips. It is the basic rule of goods and services trade - make better, receive much bigger. For improving the image of the destination in the eyes of customers, the tourism professionals are offering standard reciprocity tricks, as free cuisine trials, free walking tours, dancing and singing teams in restaurants and many others. All this tactics are improving the image of the place and the reciprocity background is becoming less and less visible for the customers. The strongest and in same time the weakest point about this rule is as soon as you do not know about it, it works. Reciprocity theory is applicable to the majority of products on the tourist market. The marketing strategies are involving psychological tricks in order to excite tourists and encourage their purchases. A perfect example of this might be voluntary tours and excursions, guided by students of faculties, merely connected to tourism: history, architecture, linguistics and etc. After gaining popularity, that organizations of young guides were united under one name - free walking tours. Reciprocity is also the main mechanism of sales in shops in tourism districts in most of Middle East countries like Egypt or Turkey, however here the effect is sometimes strengthened by additional pressure put on tourists by sellers. Reciprocity background might be found also in popular in hospitality services tipping behavior.

Reciprocity exchange theory however cannot be treated as a single explanation of all inter-personal market behavior neither in tourism neither in other markets. Such an explanation might be also found in Social Exchange Theory which is rooted in sociology and anthropology (Cook, Rice, 2003) and has been applied widely in a business context. Frémeaux and Michelson (2011) state that social and business experience has surpassed what they term as the dominant logic of exchange - 'the existential gift' - highlighting that not all giving behavior is based exclusively on the rationality and logic of reciprocity. Whereas Goss (2008), exploring emotional dynamics within 
entrepreneurial behavior, suggests a more emotionally informed understanding could improve business. Finally, Ballinger and Rockman (2010) show how relationships can change between reciprocity-based and non-reciprocitybased forms through the course of one or a short sequence of exchange.

\section{Research method}

The research were conducted in Cracow in restaurant "Morskie Oko". The restaurant is a pure example of national Polish cuisine with European standards of service. It is located in Old Town, 5 minutes from the Main Square (Plać Szepański 8) and well advertised on free tourist maps, provided by Tourist Information Offices. These are among the main reason that the place is frequently visited by international tourists, which is visible also in presented results and was important when choosing the restaurant to the research. The restaurant capacity is 140 seats. Wooden interior, music and decoration create demanded atmosphere. The investigation was made during the start of high season from March 2015 till May 2015. The choice of this restaurant was supported by technical possibilities (cooperation of employees) as well as meritorical issues, like the fact that this restaurant is concentrated mainly on catering visitors in Cracow and deals with both domestic and international tourists which helped in observing variety of behaviour of people comeing from different countries and different cultures.

The research were based on the experiment methodology. 100 accidental examples of customer service were chosen. All 100 customers were served by the same waiter. The waiter was serving all chosen guest on the highest possible level of service. He is an experienced employee with language proficiency in Polish, English, Russian and Ukrainian. $100 \%$ of guests had left tips for the service, which is not included in the price. The results were created by a comparison of two groups of observations. In 50 cases the waiter was just serving the customers and in another 50 cases the waiter was offering an extra one chewing gum with the receipt as a small gift. Details are presented in Tables 1 and 2. As the selction of customers was purely accidental it was not possible to obtain the same or similar structure of customers in both control and experimental group, however it is worth noticing that the number of Polish customers is in both cases the same.

\section{Results}

Results presented in the Tables 1 and 2 convince that the level of tips is influenced by the gratefulness which typical for the reciprocal exchange. When the waiter offered the customers regular, good service the level of tips was about $10 \%$ which is in accordance with expected tipping behavior, especially in Central and Eastern Europe. However, when a small gift was applied to enlarge customer feeling of gratefulness the ratio increased by almost 4\%. This slight change caused that the total amount of tips earned by the waiter increased by 180 PLN even though that the average bill was a bit lower in the second part of the experiment. This represents a huge financial effectiveness when compared with the cost of several pockets of chewing gum. His performance is the straight confirmation of the infallibility of reciprocity as the tool of shaping customer behavior. In the experimental group, the majority of customers left more than $15 \%$ of tips for the waiter, while only several of them, 7 out of 50 guests, left less than $10 \%$. On the other hand, dating back to the control group of the experiment, 13 out of 50 guests left less that $10 \%$ from the bill. In both parts, the highest tips were left by customers from neighboring countries of Poland: Czech Republic, Russia, Ukraine and Germany. Opposite, the lowest ones, were observed from the guests of Northern countries (Finland, Scotland, Norway, Sweden). Polish customers usually left tips a bit lower then the group average. The highest tips were received, when the sum in the receipt was fluctuating between 140-200 PLN. 
Table 1. Tips after a regular service

\begin{tabular}{ccccc}
\hline \multirow{2}{*}{ Number of customers } & \multicolumn{4}{c}{ Regular service } \\
\cline { 2 - 5 } & Nationality & Average bill amount (PLN) & Tips $\%$ & Tips amount \\
\hline 1. & England & 260.0 & 12.00 & 31 \\
1. & Finland & 140.0 & 10.00 & 14 \\
2. & France & 175.0 & 8.50 & 16 \\
2. & Greece & 356.0 & 12.00 & 43 \\
1. & Italy & 360.0 & 15.00 & 54 \\
1. & Norway & 60.0 & 10.00 & 6 \\
30. & Poland & 120.2 & 9.45 & 12 \\
2. & Russia & 236.0 & 14.00 & 40 \\
8. & Spain & 193.4 & 8.00 & 16 \\
1. & Switzerland & 190.0 & 10.00 & 19 \\
1. & Ukraine & 87.0 & 7.00 & 6 \\
\hline
\end{tabular}

Source: own elaboration.

Table 2. Tips after a service with a small gift

\begin{tabular}{ccccc}
\hline \multirow{2}{*}{ Number of customers } & \multicolumn{4}{c}{ Service with a small gift } \\
\cline { 2 - 5 } & Nationality & Average bill amount (PLN) & Tips $\%$ & Tips amount \\
\hline 1. & Czech Rep. & 311.0 & 19.00 & 59 \\
2. & England & 115.0 & 13.50 & 16 \\
5. & Germany & 129.6 & 17.00 & 23 \\
1. & Greece & 191.0 & 14.00 & 27 \\
2. & Italy & 146.5 & 17.50 & 25 \\
30. & Poland & 144.4 & 12.38 & 19 \\
2. & Russia & 129.5 & 20.00 & 26 \\
1. & Scotland & 109.0 & 5.00 & 5 \\
1. & Slovenia & 80.0 & 10.00 & 8 \\
2. & Spain & 209.5 & 10.00 & 19 \\
1. & Sweden & 167.0 & 11.00 & 18 \\
1. & Ukraine & 68.0 & 20.00 & 14 \\
\hline
\end{tabular}

Source: own elaboration.

\section{Discussion and conclusions}

Summarizing all the data, could be highlighted the sharp change in results of the gratitude amount with and without usage of reciprocity tool, namely offering free of charge product after buying main one. The results have proved, that the reciprocity trick has allowed to increase the quantity of tips more than $20 \%$, breaking the limits and already established ethics of tipping, which correspond to $10 \%$. In fact, automatic, stereotyped behavior is prevalent in people, since it is seen as most appropriate and socially approvable. Nevertheless, according to the results of the experiment, the impact of the reciprocity is overcoming attitudes and stereotyped customs. 
Received results remain in accordance with Cialdini's findings who arrived to rather similar conclusions in very different social conditions and over ten years ago (Cialdini, 2002). This proves universality of behavior driven by reciprocity. However research needs to be extended and conducted on bigger samples as particular location and small size of the sample might be pointed out as limits of presented results and conclusions. We should not conclude that similar phenomena would be observe in different kinds of gastronomy setting, in different places in Poland and throughout the world as the customrs culture factor might influence them significantly. However in presented results correlation between wealth of particular societies and the tipping behaviour was not found.

It is worth noticing that presented experiment was concentrated on relations between the employee - the waiter and the customers, however the third benefiting party in presented situation was also the restaurant. The increase of level of tipping mirrored not only increase of gratefulness to the waiter but also of satisfaction from the visit in the restaurant. This remains in accordance with the major findings of Kano (1984) and his three factor theory of perceived quality. When all basic requirements of customers (so called must-be quality and one-dimensional factors) are met the most desired way of exchanging customers satisfaction into customer delight is adding a small unexpected element to the product (satisfiers or attractive quality) (Bolster, 1993; Pouliot, 1993; Bailom, Matzler, Hinterhuber, Sauerwein, 1996). The role of such a satisfier is played by the chewing gum in presented research.

However, adding a chewing gum, or other small gifts to customers cannot be pointed out as a universal strategy for the success for all restaurants. As Löfgren and Wittel $(2005$, p. 10) pointed out, factors described by Kano are the subject of evolution and satisfiers after some time are playing the role of one-dimensional quality factors and finally they become a must-be quality factors. This means that customers are getting used to good things and it is difficult to surprise and delight them with the same added element (Żemła, 2008). In presented example that means that chewing gum as a small gift leading to a reciprocal exchange is working only in situation when the customer is not expecting that kind of gift. If many restaurants had applied this action, customers would have learned to expect the gift and being provided with a chewing gum would not increase their satisfaction. Oppositely, in case of no chewing gum they would have been unsatisfied. That is why the approach presented in the paper might be suggested only as an occasional short-time promotion, not a strategic enhancement of the service.

Involvement of a restaurant in the described relation between a waiter and a customer embraces also issues connected with code of ethics. Can such a distribution of gifts be just an employee initiative and action, even without informing the employer or this should be coordinated by the restaurant operator? Answers for those questions are crutial for the results interpretation, however those answers might be very individual and differ between particular establishments. Still, some kind of, at least, employer acceptation seems to be desirable.

\section{Reference}

Bailom, F., Matzler, K., Hinterhuber, H.H., Sauerwein, E. (1996). Must-be quality and attractive quality. In: K. Weiermair (ed.), Alpine Tourism. Sustainability Reconsidered and Redesigned. Innsbruck: University of Innsbruck.

Ballinger, G., Rockman, K. (2010). Chutes versus Ladders: anchoring events and a punctuated-equilibrium perspective on social exchange relationships. Academy of Management Review, 35 (3).

Bolster, C. (1993). Theoretical parallels between Kano's and Herzberg's theories. Center for Quality of Management Journal, 2 (4).

Cialdini, R.B. (1993). Influence: Science and practice. New York: HarperCollins.

Cialdini, R.B. (2001). Harnessing the science of persuasion. Harvard Business Review, October.

Cialdini, R. (2002). Sweetening the Till: The Use of Candy to Increase Restaurant Tipping. Journal of Applied Social Psychology, 32 (2). 
Clayson, D.E. (2004). A test of reciprocity effects in the student evaluation of instructors in marketing classes. Marketing Education Review, 14.

Clayson, D.E, Frost, T.F., Sheffet, M.J. (2006). Grades and the Student Evaluation of Instruction: A Test of the Reciprocity Effect. Academy of Management Learning \& Education, 5 (1).

Cook, K., Rice, E. (2003). Social exchange theory. In: J. Delameter (ed.), The handbook of social psychology. New York: Springer.

Diekmann, A. (2004). The power of reciprocity. Journal of Conflict Resolution, 48.

Fehr, M. (2011). The Two Sides of the Golden Rule: Living Assertively is Living Biblically. London: WestBow Press.

Frémeaux, S., Michelson, G. (2011). 'No Strings Attached': welcoming the existential gift in business. Journal of Business Ethics, 99.

Gill, C., Postlethwaite, N., Seaford, R. (1998). Reciprocity in Ancient Greece. Oxford: Oxford University Press.

Goss, D. (2008). Enterprise ritual: a theory of entrepreneurial emotion and exchange. British Journal of Management, 19 (2).

Kano, N. (1984). Attractive Quality and Must-be Quality. Hinshitsu. The Journal of the Japanese Society for Quality Control, 14 (2).

Löfgren, M., Wittell, L. (2005). Kano's theory of attractive quality and packaging. Quality Management Journal, 12 (3).

Neusner, J., Chilton, B.D. (2008). The Golden Rule: The Ethics of Reciprocity in World Religions. New York: Bloomsbury Publishing.

Palmatier, R.W., Jarvis, C.W., Bechkoff, J.R, Kardes, F.R. (2009). The role of customer gratitude in relationship marketing. Journal of Marketing, 73 (5).

Pouliot, F. (1993). Theoretical issues of Kano's methods. Center for Quality of Management Journal, 2 (4).

www.merriam-webster.com/dictionary/reciprocity.

Żemła, M. (2008). The product quality of Polish ski-resorts: a case study of Silesian skiers' requirements, satisfaction and complaints. Tourism. An Interdisciplinary Journal, 56 (1).

Cite this anticle aS: Żemła, M., Gladka, A. (2016). Effectiveness of reciprocal rule in tourism: evidence from a city tourist restaurant. European Journal of Service Management, 17 (1), 57-63. DOI: 10.18276/ejsm.2016.17/1-08. 
